\title{
MECANISMOS DE ENCRUAMENTO DO AÇO INOXIDÁVEL DUPLEX UNS S32205 SUBMETIDO A LAMINAÇÃO A MORNO E RECOZIMENTO*
}

\section{Resumo}

Aline Oliveira Vasconcelos Ferreira ${ }^{1}$ Davi Silva Alves ${ }^{1}$ Carolina Arriel Pedroso Dias ${ }^{1}$ Marcela Romano Ramos de Carvalho ${ }^{1}$ João Paulo Salles Gouvêa Faria ${ }^{1}$ Dagoberto Brandão Santos ${ }^{2}$

Neste trabalho, tiras de aço inoxidável duplex UNS S32205 foram laminadas a morno a $600^{\circ} \mathrm{C}$ com $60 \%$ e $80 \%$ de redução e, em seguida, foram recozidas a $1050^{\circ} \mathrm{C}$ durante $300 \mathrm{~s}$. A tira como fornecida (laminada a quente industrialmente e recozida) também foi recozida para efeito de comparação. Avaliou-se o comportamento mecânico das amostras como fornecida, $60 \%$ e $80 \%$ por meio de ensaios de tração e microdureza Vickers, obtendo-se $779 \mathrm{MPa}, 730 \mathrm{MPa}$ e $807 \mathrm{MPa}$ de limite de resistência a tração e 265 HV, 244 HV e 256 HV de microdureza Vickers para as três condições descritas, respectivamente. Outros ensaios de microdureza foram realizados ao longo da superfície do corpo de prova fraturado em tração, indicando um aumento da dureza nas regiões mais próximas da fratura. $O$ aumento da dureza na região de estricção indicou o aparecimento da martensita induzida por deformação para as amostras laminadas a morno. Usando a derivada da curva tensão verdadeira em função da deformação verdadeira, $(\mathrm{d} \sigma / \mathrm{d} \varepsilon)$, avaliou-se o comportamento de encruamento do aço para as três condições. Juntamente com os exames por microscopia eletrônica de alta resolução e difração de raios $X$, buscou-se uma interpretação dos mecanismos de deformação plástica envolvidos no processo de encruamento. Em determinados estágios, observouse uma mudança da inclinação para um regime estável, indicando a ocorrência de outros mecanismos de deformação plástica, diferentes do escorregamento de deslocações. A martensita induzida por deformação foi considerada responsável pelo aumento da taxa de encruamento do aço, i.e., por ser obstáculo à movimentação das deslocações e por postergar a formação da estricção.

Palavras-chave: Efeito TRIP; Encruamento; Expoente de encruamento; aço inox duplex

\section{WORK HARDENING MECHANISM OF DUPLEX STAINLESS STEEL UNS S32205 SUBMITTED TO WARM ROLLING AND ANNEALING}

\section{Abstract}

In this work, stainless steel duplex strips UNS S32205 were warm rolled at $600^{\circ} \mathrm{C}$ with $60 \%$ and $80 \%$ thickness reduction and then annealed at $1050{ }^{\circ} \mathrm{C}$ for $300 \mathrm{~s}$. The strip as supplied (hot rolled industrially and annealed) was also annealed for comparison purposes. The mechanical behavior of the samples as supplied, $60 \%$ and $80 \%$ was evaluated by tensile and microhardness tests, obtaining $779 \mathrm{MPa}, 730 \mathrm{MPa}$ and 807 $\mathrm{MPa}$ of tensile strength and $265 \mathrm{HV}, 244 \mathrm{HV}$ and $256 \mathrm{HV}$ of Vickers microhardness for the three conditions described, respectively. Further microhardness tests were performed along the surface of the tensile fractured test specimen, indicating an increase in hardness in regions closer to the fracture. The increase of the hardness in the necking region indicated the appearance of the deformation induced martensite for the warm rolling and as received samples. Using the derivative of the true stress curve as a function of the true deformation, $(d \sigma / d \varepsilon)$, the working hardening behavior of the steel for the three conditions was evaluated. Through high-resolution scanning electron microscopy and X-ray diffraction, the plastic deformation mechanisms involved in the work hardening process were interpreted. At certain stages, a change of inclination was observed for an increasing in true strain, indicating the occurrence of other mechanisms of plastic deformation other than slip dislocations. The strain induced martensite 
contributes for increasing the steel work hardening rate, as it is an obstacle to the movement of the dislocations and to the necking formation.

Keywords: Trip effect; Duplex stainless steel; Work hardening; Austenite; Texture

1 Graduando em Engenharia Metalúrgica - Departamento de Engenharia Metalúrgica e de Materiais, Universidade Federal de Minas Gerais - Belo Horizonte - MG - Brasil.

2 Professor Titular, Dr., Departamento de Engenharia Metalúrgica e de Materiais, Universidade Federal de Minas Gerais - Belo Horizonte - MG - Brasil. 


\section{INTRODUÇÃO}

Os aços inoxidáveis duplex (AID) são aços bifásicos, contendo ferrita ( $\alpha$ ) e austenita ( $\mathrm{Y})$ na mesma fração volumétrica. Esta microestrutura confere ao aço alta resistência mecânica, ductilidade, resistência à corrosão e boa soldabilidade. Devido às suas propriedades, são empregados nas indústrias petroquímicas, papel e celulose, óleo e gás [1-3].

O efeito TRIP (Transformation Induced Plasticity), consequência da formação de martensita por deformação a partir da austenita, já foi observado nos aços duplex [46]. A martensita induzida por deformação (SIM) aumenta a ductilidade e a taxa de encruamento do aço por ser um obstáculo à movimentação das deslocações [7-10]. Nos AID a fase austenítica se transforma diretamente na martensita $\alpha$, de estrutura cúbica de corpo centrado, por causa de sua baixa energia de falha de empilhamento (EFE) [11,12]. Também é possível a formação da martensita $\alpha^{\prime}$ a partir da martensita $\varepsilon$ [11-13]. As fases constituintes do aço duplex possuem diferentes mecanismos de deformação. A fase ferrítica, cúbica de corpo centrado, se deforma pelo escorregamento de deslocações. Já a austenita, cúbica de face centrada, se deforma tanto pelo escorregamento planar de deslocações, quanto pelo efeito TRIP e também por maclação mecânica TWIP (Twinning Induced Plasticity) [12-14].

Neste trabalho, tiras de aço inoxidável duplex UNS S32205 foram processadas por laminação a morno e recristalizadas por recozimento isotérmico a $1050^{\circ} \mathrm{C}$ durante 300 s. A primeira condição examinada corresponde à fornecida pelo fabricante, i.e., laminada a quente industrialmente e recozida a $1100^{\circ} \mathrm{C}$ por $30 \mathrm{~min}$, e outras duas condições correspondem às amostras que foram laminadas a morno a $600^{\circ} \mathrm{C} \mathrm{com}$ $60 \%$ e $80 \%$ de redução, e, em seguidas, recozidas. Avaliou-se o comportamento mecânico das amostras por meio de ensaios de tração e microdureza a temperatura ambiente.

Como o trabalho a quente requer energia térmica muito dispendiosa, existe uma tendência de trabalho mecânico a temperaturas mais baixas. Trabalhar a temperatura mais baixa, como o trabalho a morno, pode produzir um material próximo da sua forma final e reduzir ou eliminar o trabalho a frio, o que requer forças de trabalho mais altas nas usinas. O tratamento térmico adicional em algumas aplicações também pode ser evitado [15-18].

A motivação para a realização deste trabalho é proveniente da ampla aplicação dos aços inoxidáveis duplex em diversos setores da indústria. Essas aplicações, e as transformações de fases induzidas durante a deformação e seu efeito nas propriedades ainda não estão inteiramente compreendidos, principalmente quando são processadas mecanicamente em temperaturas bem abaixo daquelas usadas no trabalho a quente, tornando-se de grandes interesses científico, tecnológico e industrial [1-3,15-18]. Nesse sentido, a laminação a morno do AID é pouco explorada; somente alguns trabalhos com o AID de $12 \%$ Ni foram encontrados $[6,18]$.

\section{MATERIAL E MÉTODOS}

O trabalho utilizou o aço inoxidável duplex UNS 32205 laminado a quente e recozido com espessura de $5,01 \mathrm{~mm}$ de procedência industrial. A composição química fornecida pelo produtor é descrita na Tabela 1. 
Tabela 1. Composição química (\% em peso) do aço inoxidável UNS S32205

\begin{tabular}{|c|c|c|c|c|c|c|c|c|c|}
\hline Elemento & $\mathbf{C}$ & $\mathbf{M n}$ & $\mathbf{S i}$ & $\mathbf{C r}$ & $\mathbf{N i}$ & $\mathbf{M o}$ & $\mathbf{N}$ & $\mathbf{P}$ & $\mathbf{S}$ \\
\hline \% em peso & 0,026 & 1,83 & 0,25 & 22,43 & 5,44 & 3,04 & 0,15 & 0,03 & 0,0002 \\
\hline
\end{tabular}

As temperaturas de transformação de fases foram calculadas $865 \mathrm{~K}$ e $1009 \mathrm{~K}$ $\left(592^{\circ} \mathrm{C}\right.$ e $\left.736^{\circ} \mathrm{C}\right)$, respectivamente, usando o software termodinâmico ThermoCalc ${ }^{\mathrm{TM}}$. Posteriormente, as amostras foram submetidas a laminação a morno, realizadas em um laminador de laboratório Fröhling. Antes da laminação a morno, a amostra foi encharcada durante $30 \mathrm{~min}$ a $600^{\circ} \mathrm{C}$. Para essa temperatura, a precipitação das fases deletérias demanda horas para se iniciar $[3,6]$. Em seguida, a laminação a morno foi realizada até uma espessura de $1,5 \mathrm{~mm}$ em onze passes $(\varepsilon=$ 0,72 ). Após cada passe, foi aplicado o reaquecimento necessário durante $15 \mathrm{~min}$ para garantir a temperatura da tira de $600^{\circ} \mathrm{C}$ antes do próximo passe. Após a última passagem, a tira foi arrefecida até a temperatura ambiente no ar. Foram alcançadas reduções de 60 e $80 \%$ na espessura.

Para a temperatura de $600^{\circ} \mathrm{C}$, a literatura e o software utilizado relatam a existência de cinco fases: austenita, ferrita, fases $\sigma$ e $x$ e o carboneto do tipo $\mathrm{M}_{23} \mathrm{C}_{6}$. No entanto, Padilha et al. [1] registram que o início da formação dessas três últimas fases acontece após um período de $3 \mathrm{~h}$ de aquecimento, na temperatura de $600^{\circ} \mathrm{C}$. Desse modo, é possível o processamento termomecânico do AID a $600^{\circ} \mathrm{C}$ sem que ocorra a precipitação das fases deletérias.

A microestrutura foi examinada por meio de microscopia óptica (MO) e eletrônica de varredura (MEV). A preparação das amostras para a MO e MEV seguiram o procedimento metalográfico convencional de corte, lixamento e polimento com pasta de diamante, seguido de ataque químico com o reativo Behara ou de ataque eletrolítico com ácido oxálico (10\% volume em água destilada). Todas as micrografias foram obtidas no plano normal versus plano longitudinal contendo a direção de laminação, isto é, plano de espessura.

Para determinar quantitativamente as fases presentes, as amostras do aço foram submetidas à difração de raios $X$ usando um passe de $0,02^{\circ} \mathrm{s}^{-1}$ e $2 \theta$ variando de $20^{\circ}$ a $110^{\circ} \mathrm{em}$ um instrumento da PanAnalytical, modelo Empyrean. O software Origin ${ }^{\mathrm{TM}}$ foi utilizado para análise quantitativa pela integração dos principais picos de difração (para ferrita e austenita).

A microdureza foi medida usando um instrumento de microdureza Future Tech FM700 Vickers carregado para 2,98 N por $10 \mathrm{~s}$. O valor médio foi calculado a partir de 20 indentações. O teste de tração foi realizado em uma máquina Instron 5582, usando o software Blue Hill para aquisição de dados à temperatura ambiente, com uma taxa de deformação de $10^{-3} \mathrm{~s}^{-1}$. Os espécimes foram usinados de acordo com as dimensões de sub-tamanho com seção retangular de $25,4 \times 6 \times 1,1 \mathrm{~mm}$ estabelecidos pela norma ASTM A- 370-17.

\section{RESULTADOS E DISCUSSÃO}

\subsection{Difração de raios $X$}

Os difratogramas das amostras como recebida e laminadas a morno com reduções de $60 \%$ e $80 \%$ são mostrados na Figura 1a-c. Os resultados quantitativos estão resumidos na Tabela 2. Eles confirmaram a presença de austenita y e ferrita a nas amostras, em proporções próximas a $35 \%$ de a e $65 \%$ de $y$. Existe uma diferença entre as condições de laminação a quente da amostra como recebida e de 
laminação a morno em ambas reduções. Não se observou a presença de fases deletérias, tais como $\sigma, \mathrm{X}$, carbonetos e nitretos, nos difratogramas.

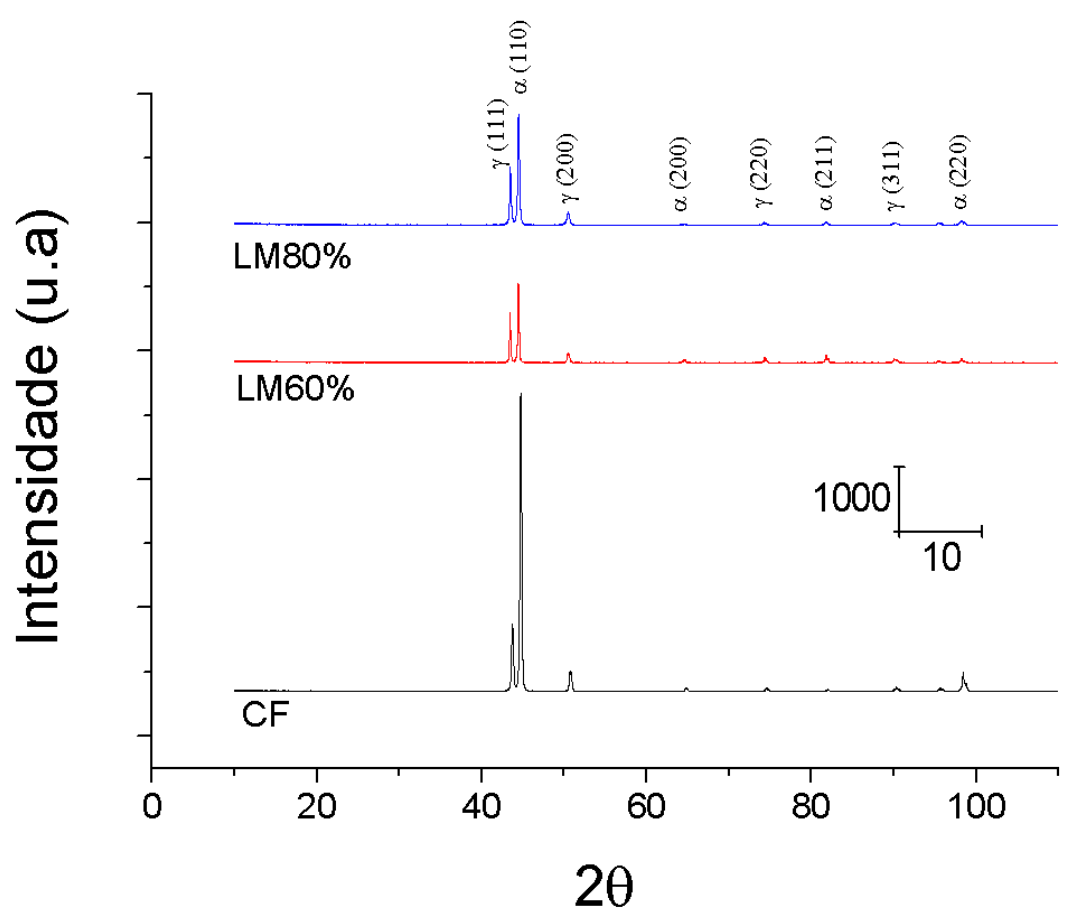

Figura 1. Difratogramas do AID 2205 recozido a $1050^{\circ} \mathrm{C} / 5 \mathrm{~min}$ : como fornecido (CF) e após laminação a morno com $60 \%$ e $80 \%$ de redução de espessura.

Tabela 2. Fração volumétrica de ferrita $(\alpha)$ e austenita $(\gamma)$ para as amostras do aço 2205 recozido a $1050^{\circ} \mathrm{C} / 300 \mathrm{~s}$, laminada a morno com $80 \%$, laminada a morno com $60 \%$ e como fornecida

\begin{tabular}{ccc} 
Condição (recozida a $\mathbf{1 0 5 0 ^ { \circ }} \mathbf{C}$ por $\mathbf{3 0 0}$ s) & $\gamma$ & $\boldsymbol{\alpha}$ \\
\hline Laminada a morno $80 \%$ & 38 & 62 \\
\hline Laminada a morno $60 \%$ & 43 & 57 \\
\hline Como fornecida & 24 & 76
\end{tabular}

\subsection{Microscopia óptica e eletrônica de varredura}

A Figura 2 ilustra as micrografias ópticas ao longo da superfície do corpo de tração até se alcançar a região da fratura das amostras nas condições: (a) como fornecida; (b) laminada a morno com $60 \%$; (c) laminada a morno com $80 \%$. À esquerda da Figura 2, tem-se a região de fratura do corpo de prova (CP) de tração e à direita tem-se a região do raio de concordância do CP. Esta superfície ilustrada na Figura 2 corresponde ao plano de laminação, mesmo assim, fica acentuada a distribuição das lamelas de ferrita e austenita na região distante da fratura. À medida que se aproxima da estriç̧ão, ocorre uma mudança na direção de alinhamento das lamelas, bem como um refino acentuado da microestrutura (Figura 2 à esquerda). A rotação das lamelas se deve à busca do material em selecionar os planos de escorregamento mais favoráveis; no caso da austenita são os planos $\{111\}$. A ferrita, por sua vez, devido à continuidade da microestrutura, tem que acomodar toda essa deformação plástica [19-21]. 

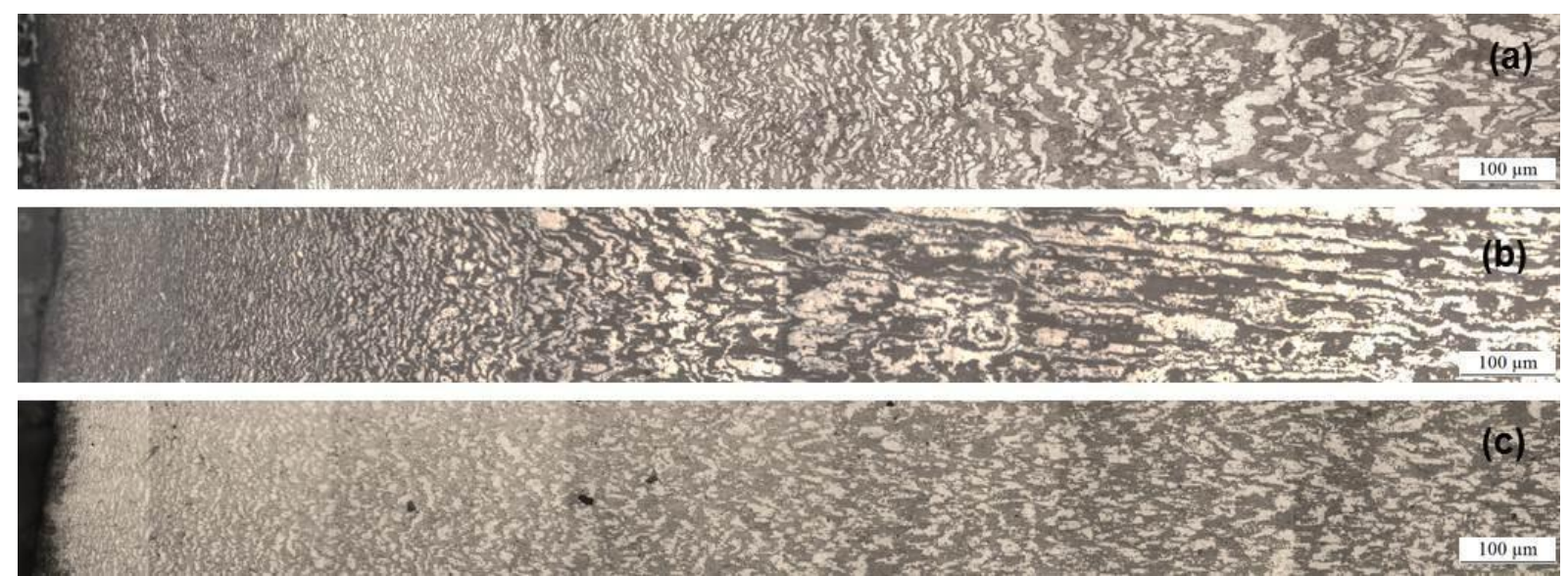

Figura 2. Micrografias ópticas do perfil de fratura do aço em estudo nas condições: (a) como fornecida; (b) laminado a morno com 60\%; (c) laminado a morno com $80 \%$.

Na Figura 3 podem ser observados os detalhes dessa evolução da microestrutura em função da deformação no ensaio de tração. Na Figura 4a, b são ilustrados os detalhes da formação de martensita no interior dos grãos austeníticos. A região examinada corresponde à estricção.

Nas Figuras 5 e 6 estão plotados os resultados dos ensaios de tração (Figura 5) e da derivada da tensão verdadeira versus deformação verdadeira (Figura 6), ou seja, a taxa de encruamento. Os resultados de resistência e ductilidade são bem semelhantes comparando-se a três condições processadas. Contudo, esses são muito importantes do ponto de vista da aplicação industrial do aço, pois foram alcançados valores compatíveis com aqueles reportados na literatura [19,21,22]. Alguns desses trabalhos fizeram o uso da deformação plástica intensa (SPD) [7,22].

$\mathrm{Na}$ Tabela 3, são resumidos os resultados de microdureza Vickers e novamente, são bem similares para as três condições.

Resultados bastante significativos são plotados na Figura 7, i.e., o perfil de dureza em função da extremidade fraturada. Nota-se que os valores de dureza alcançados são mais altos para as amostras que foram previamente laminadas a morno. Em princípio, maior fração volumétrica de martensita está sendo formada.

Durante os vários estágios ou etapas da deformação, as estruturas de deslocações irão evoluir para a formação de uma subestrutura. Essa por sua vez pode se transformar em subgrãos e eventualmente em nano-grãos. Nas áreas correspondentes à austenita, o refinamento da microestrutura é muito mais intenso. A deformação se dá ao longo do plano de deslizamento de fácil escorregamento $\{111\}$; juntamente com uma intensa maclação mecânica, i.e., segundo Maj et al. [14]. A mudança abrupta na taxa de encruamento, para uma deformação verdadeira de 0,075 , revela que essa taxa tem seu comportamento alterado pela transformação da austenita em martensita (SIM). Contudo, como já comentado, a maclação mecânica da austenita é também um mecanismo atuante. Nesse sentido, o encruamento total da liga duplex não é somente controlado pela quantidade acumulada da transformação SIM, mas principalmente pelo endurecimento por deformação da austenita não transformada remanescente e pela própria ferrita $[9,21,22]$. 

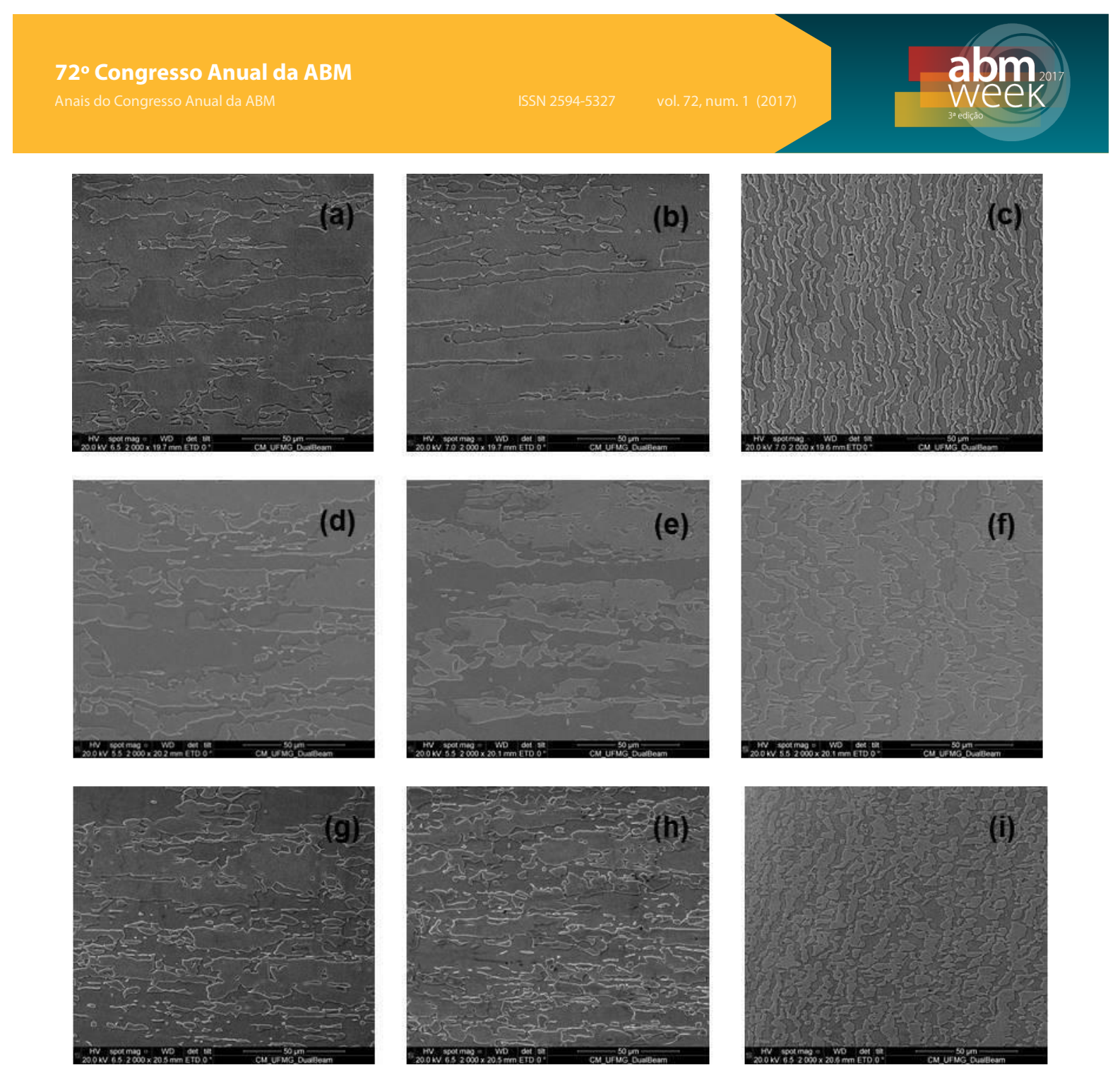

Figura 3. Micrografias obtidas no MEV do aço 2205 recozido a $1050^{\circ} \mathrm{C} / 5$ min nas condições: como fornecida (a) cauda, (b) meio, (c) ponta; laminado a morno 60\% (d) cauda, (e) meio, (f) ponta; laminado a morno $80 \%$ (g) cauda, (h) meio, (i) ponta.
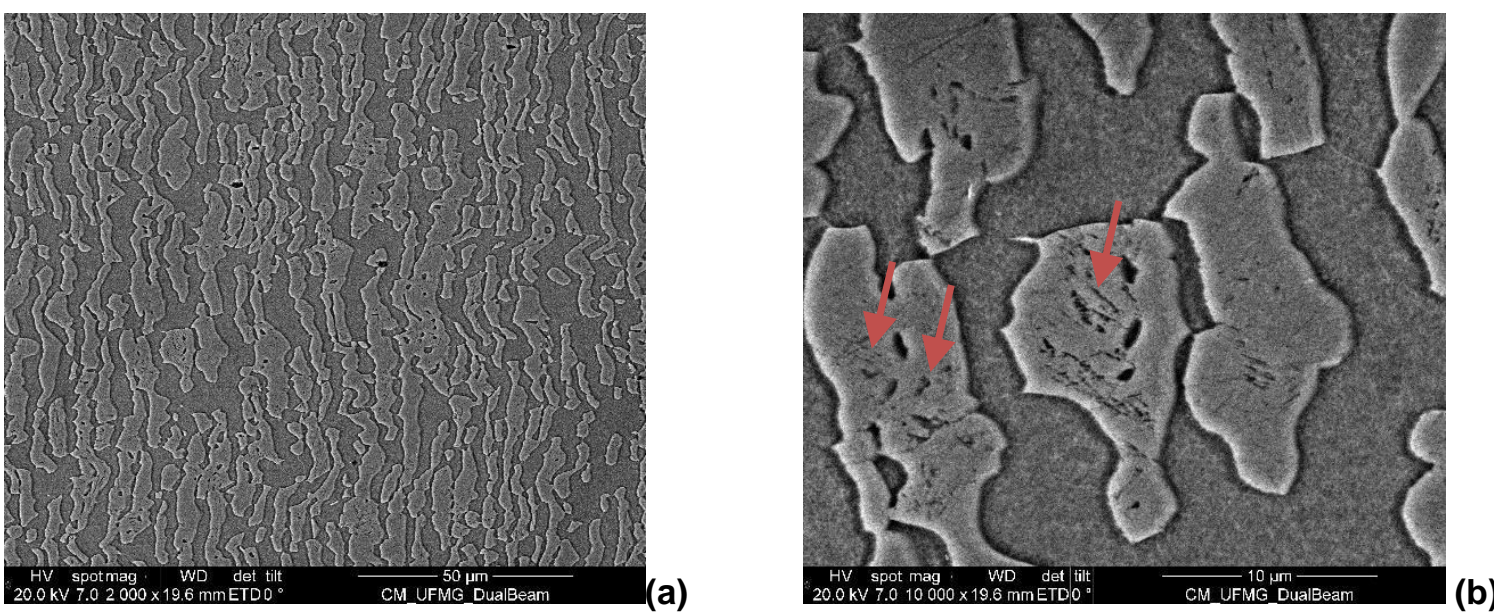

Figura 4. Micrografias obtida no MEV do aço 2205 recozido a $1050^{\circ} \mathrm{C} / 300 \mathrm{~s}$ após ensaio de tração a temperatura ambiente na condição como fornecida (a) ponta e (b) detalhe da micrografia apresentada em (a); traços de martensita $\alpha^{\prime}$, indicadas por setas.

A taxa de encruamento $(\Theta=d \sigma / d \varepsilon)$ das três amostras de AID recozidas é caracterizada por comportamentos não usuais em suas várias etapas, como ilustrado na Figura 6. De modo claro, após uma queda acentuada no encruamento 
para a transição elastoplástica, as taxas de encruamento das três amostras apresentam uma diminuição linear idêntica para cerca de $2000 \mathrm{MPa}$. Com o aumento da tensão no ensaio de tração, a queda acentuada na taxa de encruamento é interrompida e, em seguida, esta mantém um valor aproximadamente constante, com tendência à diminuição. Esses eventos acontecem para as três condições de processamento das amostras. Por exemplo, a taxa de encruamento da amostra como fornecida reduz de $2000 \mathrm{MPa}$ para 1000 $\mathrm{MPa}$ de forma suave. Por sua vez, para as amostras previamente laminadas a morno (60 e $80 \%)$ a taxa de encruamento reduz em proporções muito próximas da amostra como fornecida. O comportamento de encruamento em vários estágios, comum nas ligas com baixa energia de falha de empilhamento (SFE) que apresentam mecanismos secundários de deformação plástica [19,21,23], foi observado nas três amostras. As taxas de encruamento diminuem monotonamente até uma deformação verdadeira de 0,05 a 0,075, dependo da amostra examinada, vide Figura 6, estágio I. No entanto, ainda na Figura 6 percebe-se que a taxa tende a diminuir para as deformações verdadeiras na faixa de 0,075 a 0,015 e, posteriormente, de 0,15 a 0,25 (observar setas na Figura 6). Comportamento similar foi observado por $\mathrm{Yi}$ et al. trabalhando com o encruamento de aços inoxidáveis austeníticos metaestáveis com formação grãos austeníticos contendo nanomaclas [11].

A liga duplex em tela mostrou quatro estágios distintos de encruamento. As etapas de encruamento descritos aqui não correspondem aos estágios clássicos de endurecimento do trabalho de materiais mono ou policristalinos [19]. Todas as três amostras exibem taxas de encruamento de deformação verdadeiras, quase idênticas no estágio II, como mencionada acima $(0,05$ a 0,075$)$. No estágio III, ambos os mecanismos de deformação estão atuando: deslizamento de deslocações, formação da martensita; e a correspondente deformação daquela fração já formada. Finalmente, o estágio IV é caracterizado por uma diminuição ainda suave do endurecimento por deformação para todas as três condições, que ocorre em intensidade ligeiramente maior para laminação a morno com $80 \%$ de redução $(0,33)$, imediatamente antes do alongamento uniforme máximo (Figura 6).

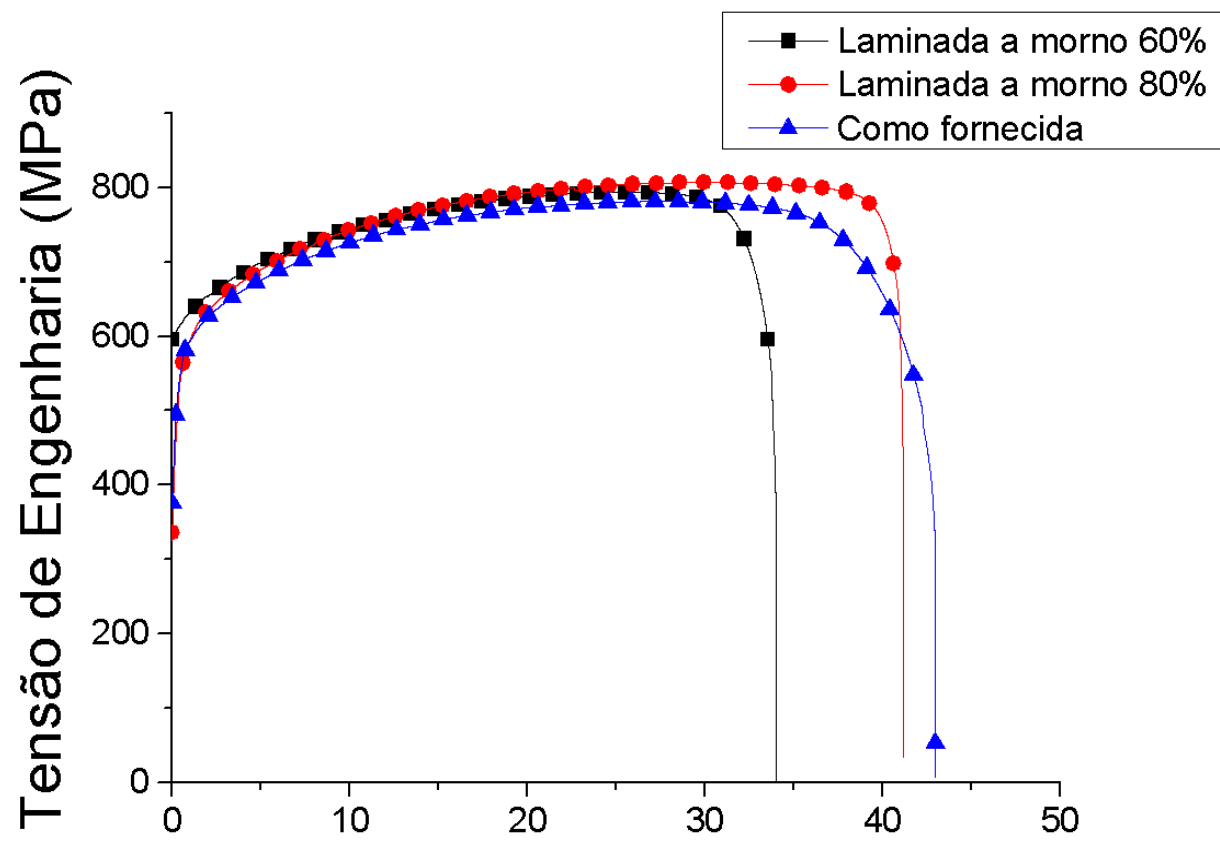


Figura 5. Curva de engenharia tensão-deformação para as amostras nas condições: como fornecida (CF), laminada a morno $60 \%$ e laminada a morno $80 \%$.

Tabela 3. Resultados dos testes de microdureza Vickers (2,97 N)

\begin{tabular}{cc}
\hline Condição (recozida a $\mathbf{1 0 5 0 ^ { \circ } \mathrm { C } \text { por } \mathbf { 3 0 0 } \text { s) }}$ & $\mathbf{H V}$ \\
\hline Como fornecida & $265 \pm 7$ \\
\hline Laminada a morno $60 \%$ & $244 \pm 5$ \\
\hline Laminada a morno $80 \%$ & $256 \pm 6$ \\
\hline
\end{tabular}

A partir da análise das curvas $d \sigma / d \varepsilon$, Figura 6, foram comentados os determinados estágios do processo de encruamento. Um comportamento diferente do usual acontece com a taxa de encruamento, que muda de um regime decrescente para um regime de patamar. Essa mudança pode ser explicada por outros mecanismos distintos do deslizamento de deslocações, ou seja, pela formação de martensita induzida devido à deformação plástica (efeito TRIP). Sendo a austenita uma fase com baixa energia de falha de empilhamento, ao ser submetida a uma tensão de deformação, há a formação de várias falhas de empilhamento, que, por sua vez, fornecem resistência ao deslizamento cruzado das deslocações dissociadas. Há portanto, um aumento da resistência mecânica do material, da taxa de encruamento e, portanto, do seu alongamento uniforme. Além disso, o aumento da microdureza do aço, Figura 7, para as três condições descritas neste trabalho (CF, 60\%, 80\%), em função da proximidade da região da fratura, corroboram para o indício de formação de martensita induzida por deformação plástica, pois essa é uma fase dura.

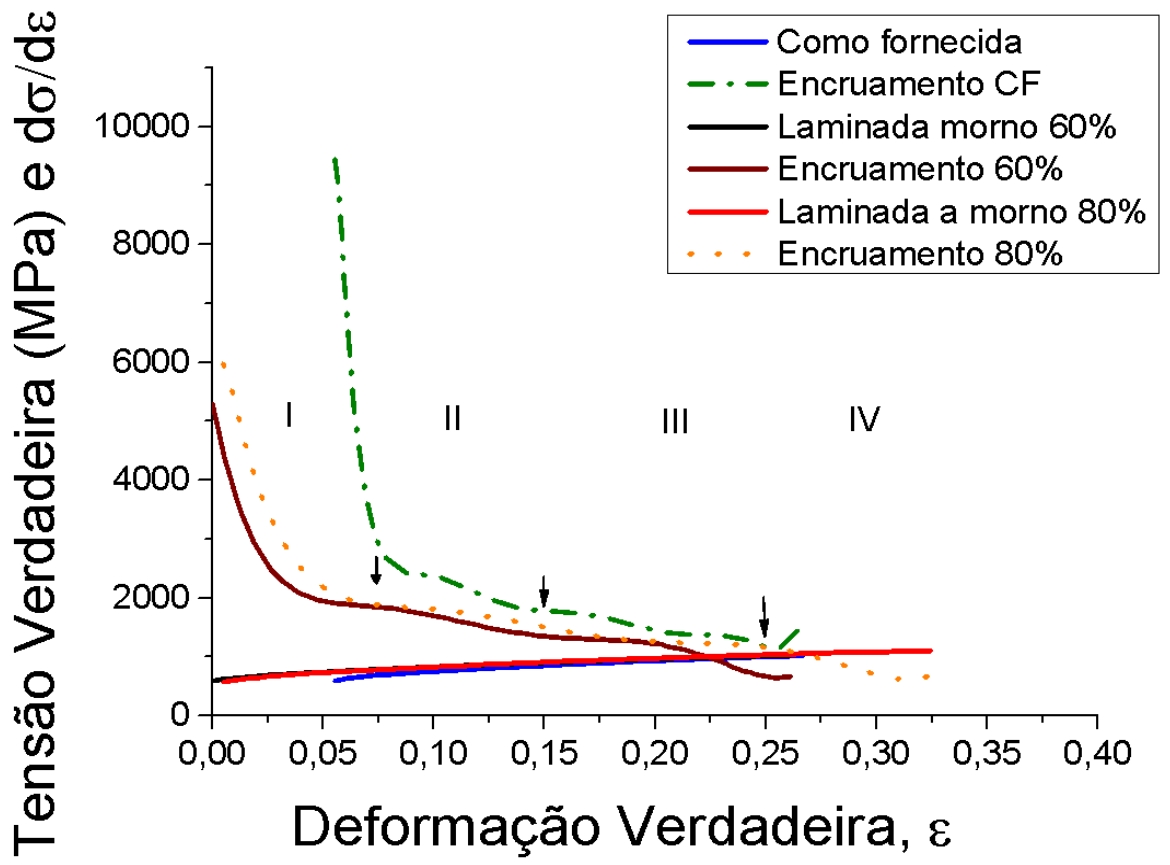

Figura 6. Curvas das taxas de encruamento e tensão verdadeira versus deformação verdadeira para as condições como fornecida (CF), laminada a morno com $60 \%$ e laminada a morno com $80 \%$. 


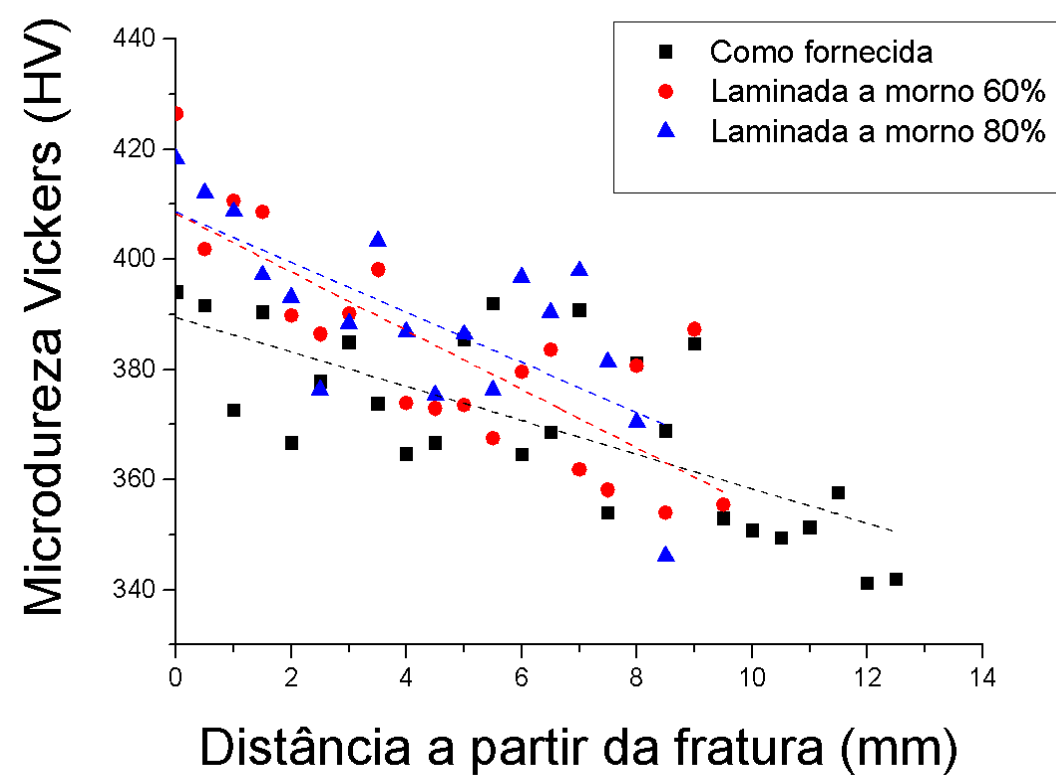

Figura 7. Variação da microdureza Vickers em função da distância a partir da fratura no corpo de prova após ensaio de tração.

\section{CONCLUSÕES}

Avaliou-se o comportamento mecânico das amostras como fornecida, $60 \%$ e $80 \%$ laminadas a morno por meio de ensaios de tração e microdureza Vickers, obtendose $779 \mathrm{MPa}, 730 \mathrm{MPa}$ e $807 \mathrm{MPa}$ de limite de resistência a tração e $265 \mathrm{HV}, 244 \mathrm{HV}$ e $256 \mathrm{HV}$ de microdureza Vickers para as três condições descritas, respectivamente. O alongamento total para todas as amostras foi em torno de $40 \%$. Outros ensaios de microdureza foram realizados ao longo da superfície do corpo de prova fraturado em tração, indicando um aumento da dureza nas regiões mais próximas à fratura. $\mathrm{O}$ aumento da dureza na região de estricção indicou o aparecimento da martensita induzida por deformação para as amostras laminadas a morno e como fornecida. Usando a derivada da curva tensão verdadeira em função da deformação verdadeira, $(\mathrm{d} \sigma / \mathrm{d} \varepsilon)$, avaliou-se o comportamento de encruamento do aço para as três condições, juntamente com os exames por microscopia eletrônica de alta resolução e difração de raios $X$. Os mecanismos de deformação plástica envolvidos no processo de encruamento envolvem estágios definidos. Observou-se uma mudança da inclinação nas curvas da taxa de encruamento para um regime de patamar, indicando a ocorrência de outros mecanismos de deformação plástica diferentes do escorregamento de deslocações. A martensita induzida por deformação contribui para o aumento da taxa de encruamento do aço por se traduzir em obstáculos à movimentação das deslocações e postergar a formação da estriç̧ão.

\section{Agradecimentos}

Os autores agradecem a CAPES-PROEX-PPGEM/UFMG (Programa de PósGraduação em Engenharia Metalúrgica, de Materiais e de Minas da Universidade Federal de Minas Gerais); ao CNPq e à FAPEMIG pelo suporte financeiro.

\section{REFERÊNCIAS}


1. Padilha AF, Plaut RL. Phase Transformation and Microstructure. In: Armas IA, Moreuil SD. Duplex Stainless Steels. London: ISTE Ltd and John Wiley \& Sons; 2009. p. 115139.

2. Fargas G, Akdut N, Anglada M, Mateo, A. Microstructural Evolution during Industrial Rolling of a Duplex. ISIJ International. 2008;48(11):1596-1602.

3. Wessman S, Pettersson R, Hertzman, S. On phase equilibria in duplex stainless steels. Steel Research International. 2010;81(5):337-346.

4. Choi JY, Ji HJ, Hwang SW, Park KT. Effects of Nitrogen Content on TRIP of Fe-20Cr$5 \mathrm{Mn}-\mathrm{xN}$ Duplex Stainless Steel. Materials Science Engineering A. 2011;534:673- 680.

5. Tavares SSM, Pardal JM, Abreu HFG, Nunes CS, Silva MR. Tensile Properties of Duplex UNS S32205 and Lean Duplex UNS S32304 Steels and the Influence of Short Duration 475으 Aging. Materials Research. 2012;15(6):859-864.

6. Bhattacharjee PP, Zaid M, Sathiaraj GD, Bhadak B. Evolution of microstructure and texture during warm rolling of a duplex steel. Metallurgical and Materials Transactions A. 2014;4(45):2180-2191.

7. Wan J, Ruan H, Shi S. Excellent combination of strength and ductility in $15 \mathrm{Cr}-2 \mathrm{Ni}$ duplex stainless steel based on ultrafine-grained austenite phase. Materials Science Engineering A. 2017;(690):93-103.

8. Chiu PK, Weng KL, Wang SH, Yang JR, Huang YS, Fang J. Low-cycle fatigue-induced martensitic transformation in SAF 2205 duplex stainless steel. Materials Science and Engineering A. 2005;(398):349-359.

9. Choi JY, Ji HJ, Hwang SW, Park KT. Effects of nitrogen content on TRIP of $\mathrm{Fe}-20 \mathrm{Cr}-$ $5 \mathrm{Mn}-\mathrm{xN}$ duplex stainless steel. Materials Science Engineering A. 2011;(534):673-680.

10. Choi JY, Ji JH, Hwang SW, Parl KT. TRIP aided deformation of a near-Ni-free, Mn-N bearing duplex stainless steel. Materials Science and Engineering A. 2012;(535):32-39.

11. Yi HY, Yan FK, Tao NR, Lu K. Work hardening behavior of nanotwinned austenitic grains in a metastable austenitic stainless steel. Scripta Materialia. 2016;114:133-136.

12. Maetz JY, Cazottes S, Verdu C, Kleber X. Precipitation and Phase Transformations in 2101 Lean Duplex Stainless Steel during Isothermal Aging. Metallurgical and Materials Transactions A. 2016;(47):239-253.

13. Padilha AF, Aguiar DJM, Plaut RL. Duplex Stainless Steels a Dozen of Significant Phase Transformations. Defect and Diffusion Forum. 2012;322:163-174.

14. Maj P, Cieślaka BA, Mizeraa J, Pachlab W, Kurzydłowski KJ. Microstructure and mechanical properties of duplex stainless steel subjected to hydrostatic extrusion. Materials Characterization. 2014;93:110-118.

15. Hawkins DN, Shuttleworth AA. The Effect of Warm Rolling on the Structure and Properties of a Low-Carbon Steel. J Mech Working Techn.1979;2:333-345.

16. Akbari GH, Sellars CM. Microstructural Development During Warm Rolling of IF Steel. Acta Materialia.1997;45(12):5047-5058.

17. Santos DB, Bruzszek RK, Rodrigues PCM, Pereloma EV. Formation of Ultra-Fine Ferrite Microstructure in Warm Rolled and Annealed C-Mn Steel. Materials Science Engineering A. 2003;346:189-195.

18. Zaid M, Bhattacharjee PP. Electron backscatter diffraction study of deformation and recrystallization textures of individual phases in a cross-rolled duplex steel. Materials Characterization. 2014;(96):263-272

19. Pierce DT, Jiménez JA, Bentley J, Raabe D, Wittig JE. The influence of stacking fault energy on the microstructural and strain hardening evolution of $\mathrm{Fe}-\mathrm{Mn}-\mathrm{Al}-\mathrm{Si}$ steels during tensile deformation. Acta Materialia. 2015;100:178-190

20. Padilha AF, Plaut RL, Rios PR. Annealing of cold-worked austenitic stainless steels. ISIJ International. 2003;43(2):135-143..

21. Hamada AS, Karjalainen LP, Misra RDK, Talonen J. Contribution of deformation mechanisms to strength and ductility in two $\mathrm{Cr}-\mathrm{Mn}$ grade austenitic stainless steels. Materials Science Engineering A. 2013;559: 336-344. 
22. Chen L, Yuan FP, Jiang P, Wu XL. Mechanical properties and nanostructures in a duplex stainless steel subjected to equal channel angular pressing. Materials Science and Engineering A. 2012;551:154-159.

23. Soares GC, Rodrigues MCM, Santos LA. Influence of temperature on mechanical properties, fracture morphology and strain hardening behavior of a 304 stainless steel. Materials Research. In press. 2017:DOI: http://dx.doi.org/10.1590/1980-5373-MR-20160932. 